1830 HBEAG SEROCONVERSION IN CHILDREN INFECTED DURING EARLY CHILDHOOD WITH HEPATITIS B VIRUS

doi:10.1136/archdischild-2012-302724.1830

MR Hasanjani Roushan, A Bijani, S Ramzaninejad, M Hasanjani Roushan, MJ Soleimani Amiri, M Baiani. Infectious Diseases Research Center, Babol Medical University, Babol, Iran

Background and Aims Seroconversion of HBeAg to anti-HBe is associated with lower viral load and liver diseases. The purpose of this study was to assess the seroconversion rate of $\mathrm{HBeAg}$ to anti$\mathrm{HBe}$ in children who acquired HBV infection during childhood period.

Methods From September 1990 to December 2010, 139 HBeAg positive children were followed up. Eighty-one subjects were failure of Hepatitis B immune globulin (HBIG) and hepatitis B vaccination at birth and 58 children < 10 years who were born before 1990 and did not receive $\mathrm{HBIG}$ and vaccine. $\mathrm{HBsAg}, \mathrm{HBeAg}$, anti-HBs and anti-HBe was assessed every six months.

Results Sixty two (44.6\%) cases were males and 77 (55.4\%) were females. Mean duration of follow-up was $18 \pm 6.6$ years. Twentyfour $(17.3 \%)$ mothers were HBeAg positive and 115 (82.7\%) anti$\mathrm{HBe}$ positive. Eighty-two (59\%) children became anti-HBe positive. Seroconversion rates in the first, second and third decades were $25 \%, 63.4 \%$ and $70.5 \%$, respectively $(p=0.001)$. The children of anti-HBe positive mothers had higher seroconversion rate than the $\mathrm{HBeAg}$ positive mothers $(75 \%$ versus $33.9 \%, \mathrm{p}=0.0001)$. Time to seroconversion rates in children born to $\mathrm{HBeAg}$ positive mothers was similar to those born to anti-HBe positive mothers $(\mathrm{HR}=1.03, \mathrm{p}=0.973)$. Time to seroconversion rates in children who received hepatitis $B$ vaccine and $\mathrm{HBIG}$ was higher than those who did not $(\mathrm{HR}=6.35, \mathrm{p}=0001)$.

Conclusions $\mathrm{HBeAg}$ seroconversion in the second and the third decades were higher than the first decade. Children born to anti$\mathrm{HBeAg}$ positive mothers and those who received HBIG and hepatitis $B$ vaccine had higher seroconversion rates.

\section{RUBELLA-VACCINE EFFECTIVENESS 5YRS AFTER MASS VACCINATION: MULTI-CENTER SERA-EPIDEMIOLOGY RETROSPECTIVE COHORT STUDY}

doi:10.1136/archdischild-2012-302724.1831

'E Ahmadnezhad, 'FF Jahani, ${ }^{3} \mathrm{M}$ Karamyyar. 'Tehran University of Medical Sciences; Infectious Disease, Urmia University of Medical Sciences, Tehran; ${ }^{3}$ Pediatrices, Urmia University of Medical Sciences, Urmia, Iran

Background The vaccine has been in use since 1969. In December 2003, during mass camping for Measles/Rubella vaccination in Iran, about 33 million doses of vaccine were administered to the 5-25 yrs old people. This serological survey was conducted to evaluate the effectiveness of Rubella vaccine after $5 y$ rs of mass camping in mothers and their neonates.

Methods This was a historical-Cohort study has been done in September (2009-2010). Study population was 180 women (20-30 yrs old) who referred for pregnancy routine care. All pregnant were at first time and didn't have Rubella-history in the past 5 years. Serum samples of women were evaluated for IgG level and newborn dried blood spot samples were evaluated for IgG and IgM levels.

Results The IgG levels of mothers were 50-10 IU (27.3\%), 100$50(19.3 \%)$ and above 100 IU (53\%). All of IgM titers in newborns were negative. It was significantly relationship between level IgG of Mothers and Full-Term Newborns ( $\mathrm{OR}=3.45$, $95 \% \mathrm{CI}=1.54-7.90$ )

Conclusion The mass vaccination has been effectiveness then the routin surveillance had to evaluate the IgG levels of reproductive age's mothers.

\section{MEDICAL STUDENT ATTITUDES AND PRACTICES ASSOCIATED WITH RECEIVING HEPATITIS A VACCINE AND VACCINE ADVERSE EVENT AND EFFECT ON ACCEPTABILITY}

doi:10.1136/archdischild-2012-302724.1832

${ }^{1} Y$ Ozsurekci, ${ }^{2} \mathrm{E}$ Karadag Oncel, ${ }^{2} \mathrm{~B}$ Ertuten, ${ }^{2} \mathrm{~A}$ Kara. ${ }^{1}$ Pediatric Infectious Disease, Hacettepe University, ${ }^{2}$ Hacetepe University, Faculty of Medicine, Ankara, Turkey

Objective In this study we aimed to assess the attitudes and practices of medical students regarding hepatitis A immunization and also adverse reactions of associated with vaccine and effect on acceptability.

Methods The study was performed on 103 medical students with ages between 20 and 26 years old. All the students vaccinated by the same nurse at Hacettepe University Faculty of Medicine on 14 days in December and answered a questionnaire and follow-up form.

Results The mean student age was $21.69 \pm 0.97$ years. Pain with movement $(58.3 \%)$ and pain with touch $(38.8 \%)$ were the most common side effects at vaccination site. Despite the side effects, all of the vaccinated students wanted to receive the following dose of vaccine. Twelve of the vaccinated students $(11.7 \%)$ indicated that the reason of their vaccination was the recommendation of a pediatric infectious disease specialist. One of the major reason for not wishing vaccination was the cost for 60 of them (58.3\%).

Conclusions The cost of vaccination and recommendation by infection specialist may have been important to receive hepatitis A vaccination for medical students and also may be for other health care workers.

\section{ACUTE NECROTIZING ENCEPHALOPATHY OF CHILDHOOD ASSOCIATED WITH INFLUENZA A}

doi:10.1136/archdischild-2012-302724.1833

'A Welk, 'S Gehring, 'J Pohlenz, ${ }^{2} \mathrm{~J}$ Gawehn, ${ }^{3} \mathrm{G}$ Staatz, ${ }^{1} \mathrm{RG}$ Huth. 'Zentrum für Kinderund Jugendmedizin; ${ }^{2}$ Institut für Neuroradiologie; ${ }^{3}$ Klinik und Poliklinik für Diagnostische und Interventionelle Radiologie, Sektion Kinderradiologie, Universitätsmedizin Mainz, Mainz, Germany

Background Each year many children suffer from respiratory infections caused by Influenza A virus, but only a limited number experiences severe complications. One of these serious complications is an acute necrotizing encephalopathy (ANEC).

Methods We report two cases of patients with ANEC following upper airway infection. Both children were referred to our paediatric intensive care unit (PICU) due to rapid neurological deterioration and respiratory failure. None had received vaccination against influenza. A 16-year old boy presented with difficulties in speech and motor deficits. A 14-months old girl had multiple focal seizures. Her Glasgow-Coma-Scale was 4 on admittance to PICU.

Both patients received a MRI (Magnetic Resonance Imaging) of the brain. The MR imaging findings demonstrated abnormal signal intensity bilaterally in multiple cortical and subcortical regions. In both cases Influenza A was detected on a nasopharyngeal swab by using polymerase chain reaction assay.

Results Both patients were treated with oseltamivir without notable clinical improvement. The boy showed complete reconvalescence. The girl suffered from increased intracranial pressure within hours after hospital admittance needing urgent external cerebrospinal fluid drainage. Her condition was complicated by an acute respiratory distress syndrome requiring mechanical ventilation. Meanwhile her consciousness has dramatically improved, but we still expect neurological sequelae.

Conclusion To our knowledge severe complications following an infection with influenza are rare but have to be kept in mind when treating a child with respiratory infection and neurological impairment. The insufficient response to oseltamivir underlines the need 